\title{
Influence evaluation of sampling methods of the non- destructive examination on failure probability of piping based on probabilistic fracture mechanics analysis
}

\author{
Akihiro MANO*, Jinya KATSUYAMA* and Yinsheng LI* \\ *Japan Atomic Energy Agency \\ 2-4 Shirakata, Tokai-mura, Ibaraki 319-1195, Japan \\ E-mail: mano.akihiro@jaea.go.jp
}

Received: 1 November 2019; Revised: 19 December 2019; Accepted: 29 January 2020

\begin{abstract}
Non-destructive examinations (NDEs) have an important role in assurance of the structural integrity of nuclear components including pipe lines. NDEs are performed for welds in piping in accordance with the rules, which prescribe the requirements of NDE such as interval and extent of examination. In general, there are two kinds of sampling method for selecting welds to be examined in each interval considering the specified extent of examination. The first method is the fixed location sampling method, in which welds for NDEs are same in each interval, while the second method is the random location sampling method, in which welds for NDEs are selected from those not examined in the last interval. The selection of the sampling method is important in assuring the structural integrity of piping. Probabilistic fracture mechanics (PFM) analysis, which is one of rational structural integrity assessment methods, can quantitatively calculate failure probability of welds in piping by considering aging degradation mechanisms, such as stress corrosion cracking and fatigue, as well as crack detections and repair of cracked welds through NDE. In some countries, especially the United States, PFM approach has been applied to NDE, such as risk-informed in-service inspection. From such backgrounds, further application of PFM approach is increasingly expected. In this study, to investigate the applicability of PFM approach on NDE, we focused on the difference in sampling method in NDE for piping and calculated the failure probability of a typical nuclear piping considering NDEs based on the two sampling methods through PFM analysis. From the results, the quantitative influence of the difference in sampling method on failure probability was clarified.
\end{abstract}

Keywords : Probabilistic fracture mechanics, Failure probability, Pressure retaining piping, Non-destructive examination, Sampling method

\section{Introduction}

In the welds in piping of nuclear power plants (NPPs), cracks may be initiated and propagate due to aging degradation mechanisms, such as stress corrosion cracking (SCC) and fatigue during plant operation. These cracks can lead to pipe failure, e.g. the leak of inner fluid and pipe rupture, and thus non-destructive examinations (NDEs) are performed to detect them. Structural integrity assessment is carried out by the deterministic evaluation method to confirm whether continued service of the cracked piping is acceptable or not when a crack has been detected in the welds in piping. If the continued service of the cracked piping is judged as unacceptable based on the assessment, a repair or replacement has to be implemented in order to eliminate the crack from the piping. Therefore, NDEs are necessary to assure the structural integrity of piping.

NDEs are performed for welds in piping in accordance with the rules, which prescribe the requirements for NDEs such as interval and extent of examination. Here, extent of examination is defined as the ratio of number of examined welds to total welds in piping for each interval. In general, there are two kinds of sampling method for selecting welds to be examined in each interval considering the specified extent of examination. The first method is the fixed location sampling method (FLSM), where the subject welds are same in each interval (the Japan Society of Mechanical Engineers, 2012). The second method is the random location sampling method (RLSM), where the subject welds are selected from other than the welds examined in the last interval (Japan Electric Association, 1996). The selection of the sampling 
methods is considered as an important factor in NDEs to assure the structural integrity.

The probabilistic fracture mechanics (PFM) approach is expected as a more rational method of structural integrity assessment. The reason is that it can consider uncertainties in various influential factors included in the assessment and calculate a quantitative value, such as the failure probability of the cracked component, as the solutions. In Japan Atomic Energy Agency, a PFM analysis code PASCAL-SP has been developed for welds in piping in NPPs. PASCAL-SP can calculate failure probability of a weld considering crack initiation and propagation due to age-related degradation mechanisms such as SCC and fatigue, and crack detection and repair of a cracked weld through NDEs (Itoh et al., 2010). In some countries, especially the United States, PFM approach has been applied to the field of NDE such as risk informed in-service inspection (Westinghouse Electric company, 1999 and 2012). From these backgrounds, further application of PFM approach to the field of NDE is increasingly expected.

In this study, to investigate the applicability of PFM approach on NDE, we focused on the difference in sampling methods in NDE for piping and calculated failure probability of a typical nuclear piping considering NDEs based on the two sampling methods by using PASCAL-SP. Based on the PFM analysis results, as one of PFM applications in the field of NDE, the difference of the influence of sampling methods on structural integrity assessment of a piping was quantitatively discussed.

\section{PFM analysis code PASCAL-SP}

PASCAL-SP can calculate failure probability of a weld in piping system, which is denoted by $f$, considering agerelated degradation mechanisms based on Monte Carlo method. Age-related degradation mechanisms which can be considered in the evaluation are SCC, fatigue, and thermal embrittlement.

The evaluation flow of PASCAL-SP is shown in Fig. 1. At first, analysis conditions such as piping geometry, stress condition, evaluation period are specified by the user's input. Parameters and their uncertainties related to fracture mechanics evaluation are modeled as probabilistic variables. Based on the probabilistic distributions of the probabilistic variables, a number of welds are sampled. For each of the sampled welds, the fracture mechanics evaluation is performed based on the methods almost same as deterministic approach.

In the fracture mechanics evaluation, crack existence at the start of evaluation, such as a crack introduced during fabrication, or crack initiation due to SCC is considered in the inner surface of a weld. Crack orientation may be either circumferential or axial. Crack size parameters such as crack depth and aspect ratio are evaluated by following their inherent probabilistic models. For the cracked weld, NDE, crack growth evaluation, and failure judgement are performed.

NDE can be performed during plant operation. NDE time and probability of detection (POD) are considered for analysis conditions. If a crack is detected in the weld by the NDE, the crack is eliminated by repair or replacement. In this scenario, PASCAL-SP does not consider crack reinitiation.

Crack growth evaluation is performed along with time increment based on a crack growth rate (CGR) evaluation model and stress intensity factor (SIF) solutions considering the stress conditions related to operating conditions, weld residual stress (WRS), and cyclic stress due to the transients. CGR evaluation applies probabilistic evaluation models for SCC and fatigue based on the scatters of the experimental crack growth data. SIF solutions provided in codes, such as Codes for Nuclear Power Generation Facilities - the Rules on Fitness for Service for Nuclear Power Plants of the Japan Society of Mechanical Engineers (JSME FFS code) (JSME, 2012) and ASME Boiler and Pressure Vessel Code Section XI (ASME, 2015) are incorporated for circumferential and axial semi-elliptical, 360 degree, and through-wall cracks. The appropriate SIF solution corresponding to crack shape and orientation is automatically selected from among solutions which were preliminarily designated by user in the crack growth evaluation.

Failure judgement is conducted for a weld in piping alongside crack growth evaluation. For the failure of welds, three modes are considered, i.e. rupture, crack penetration, and leak. The rupture of a piping is judged using failure evaluation methods such as the limit load evaluation method and the Z-factor evaluation method (JSME, 2012). If the ratio of crack depth to wall thickness exceeds a given criterion, it is assumed that the penetration of the crack occurs. After the crack penetration, leak rate is evaluated based on the method described in the Codes for Nuclear Power Generation Facilities Rules on Protection Design against Postulated Pipe Rupture for Nuclear Power Plants- (JSME S ND1-2002) (JSME, 2002). Leak rate increases with propagation in the length direction of through-wall crack. When the leak rate is higher than a given detectable leak rate or a weld is judged to be ruptured, it is determined that the leak is detected in the weld. When any of rupture, crack penetration, and leak are judged in a weld, it is categorized as a failed one.

For sampled welds, the above evaluation process is continued until one of the following conditions is satisfied, that is, when the time of operation reaches the end of the evaluation period, or it is determined that a leak is detected, piping is ruptured, or the crack is eliminated. Finally, by using a number of above fracture mechanics evaluation results, $f$ is calculated as the ratio of the number of failed welds to the number of the total welds. 


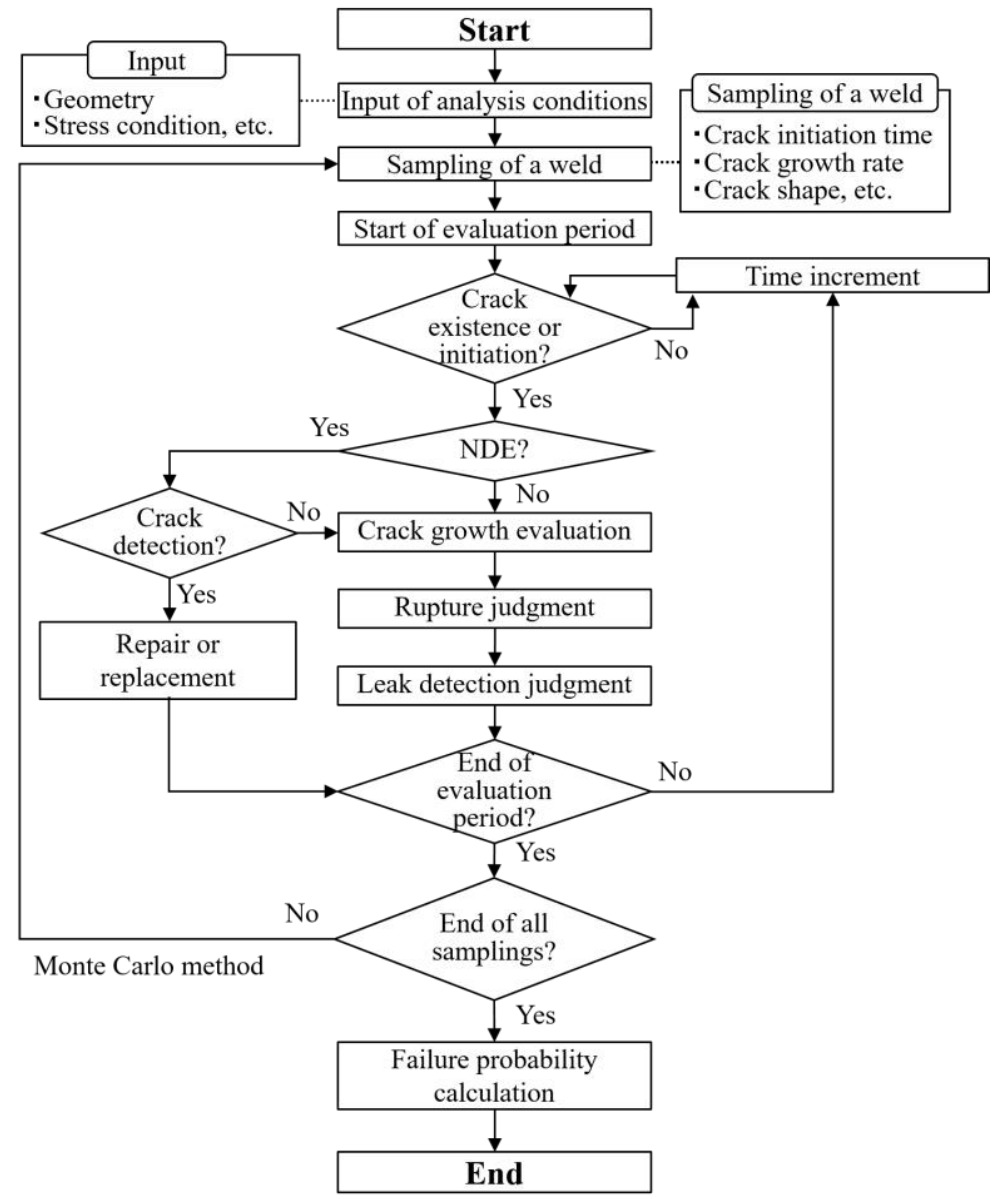

Fig. 1 Evaluation flowchart of PASCAL-SP. PASCAL-SP calculates failure probability of a weld by Monte Carlo method based on this flowchart. At first of the calculation, analysis conditions are input, and probabilistic variables related to welds are sampled. For sampled welds, crack existence or initiation is determined. After that, NDE, crack growth evaluation, judgement of rupture and leak detection are performed. Based on many iterations of this flow, failure probability is calculated.

\section{Calculation method for failure probability of piping}

In order to evaluate the influence of the two NDE-related sampling methods mentioned in chapter 1, it is necessary to calculate failure probability of piping which includes multiple welds. In this chapter, the method to calculate failure probability of piping by using the $f$ values of included welds is described.

In general, piping is determined to fail when any included welds fail. In this case, we can use Eq. (1) based on the concept of complementary event to calculate failure probability of piping.

$$
P_{F}(t)=1-\prod_{w=\mathrm{A}}^{N}\left(1-f_{w}(t)\right)
$$

where $t$ is operation time, $N$ is the number of welds included in the piping, $w$ is weld label $(w=\mathrm{A}, \mathrm{B}, \mathrm{C}, \mathrm{D}, \ldots), P_{F}$ is failure probability of piping, and $f_{w}$ is failure probability of weld $w$.

In Eq. (1), $f_{w}$ can be calculated for an individual weld considering NDEs implemented in arbitrary time by using PASCAL-SP. Thus, analysis conditions for the welds in piping can be specified so as to simulate the NDEs considering the extent of examination based on the two sampling methods. For example, when extent of examination is $25 \%$ and sampling method is the FLSM, NDEs in every 10 -year interval are considered in $25 \%$ of welds in piping, but not in the remaining $75 \%$ during plant operation. In case that extent of examination is $25 \%$ and sampling method is the RLSM, analysis conditions of welds are specified so that NDEs are performed in $25 \%$ of welds in piping that were not examined in the last 10-year interval. 


\section{Evaluation of the influence of the sampling methods on failure probability}

This chapter discusses the influence of the FLSM and RLSM on the failure probability values of piping by using the typical piping line as an example (Koriyama et al., 2009).

\subsection{Example analysis conditions}

The selected target piping system of this analysis was a part of carbon steel piping in a high pressure core spray system of a boiling water reactor (BWR). It is assumed that there were 14 welds included in the piping (Koriyama et al., 2009). Same analysis conditions except for those related to NDEs were applied for each weld.

The evaluation period was set for 40 operation years. The outer diameter and wall thickness $t$ of the piping were $267.4 \mathrm{~mm}$ and $15.1 \mathrm{~mm}$, respectively (Koriyama et al., 2009). Fatigue crack growth of initial surface crack introduced during fabrication was considered as an aging degradation mechanism which may occur and lead to failure in the target carbon steel piping. An initial circumferential semi-elliptical crack at the inner surface of each weld was taken into account together with the probability of crack existence. The initial crack depth $a$ and the aspect ratio $\beta$ were evaluated by probabilistic models expressed by lognormal distributions where $\beta=c / a$, and $c$ is the crack half-length. The probabilistic model for initial crack depth was based on the crack data obtained in main steam system piping in BWR (Brückner et al., 1982). The probabilistic model for initial aspect ratio, which was proposed for initial crack introduced during welding, was utilized (Harris et al., 1981). Parameters in these models are summarized in Table 1. The probability of crack existence is determined based on a crack density model representing crack density at the inner surface of a weld, which has been subjected to radiographic inspection after fabrication, and is expressed as Eqs. (2) and (3) (Harris and Dedhia, 1998).

$$
\begin{aligned}
& p=2 \pi R_{\mathrm{i}} f^{*} \\
& f^{*}=\max \left(\begin{array}{c}
6.55 \times 10^{-4} \exp (1.491499 t) \\
0.0022 t^{2}-0.0066 t+0.0063
\end{array}\right)
\end{aligned}
$$

where $R_{\mathrm{i}}$ is inner radius, and the probability of crack existence $p$ in each weld was considered to be 0.0925 .

In the crack growth evaluation, the probabilistic model of fatigue CGR for ferritic steel that modeled based on a lognormal distribution (Harris and Dedhia, 1998) was applied. This model is expressed by Eq. (4) and provides the probabilistic distribution of fatigue CGR equation for ferritic steel in the light water reactor environment prescribed in the JSME FFS code (JSME, 2012).

$$
\frac{\mathrm{d} a}{\mathrm{~d} N}= \begin{cases}C_{1} \Delta K^{5.95} Q & \left(\Delta K<\Delta K_{\mathrm{th}}\right) \\ C_{2} \Delta K^{1.95} Q & \left(\Delta K \geq \Delta K_{\mathrm{th}}\right)\end{cases}
$$

where $\mathrm{d} a / \mathrm{d} N$ is crack growth rate in $\mathrm{mm} /$ cycle, $C_{1}$ and $C_{2}$ are coefficients, $Q$ is probabilistic coefficient, $\Delta K$ is range of stress intensity factor in $\mathrm{MPa} \mathrm{m}^{0.5}$, and $\Delta K_{\mathrm{th}}$ is threshold in $\Delta K$. The details in $C_{1}, C_{2}, Q$ and $\Delta K_{\text {th }}$ are summarized in Table 2. The $Q$ values that sampled before the start of evaluation period were utilized until the end of the crack growth evaluations. The SIF solution for surface crack in a flat plate, provided in the JSME FFS code (JSME, 2012), was used. An inner pressure of 8.62 MPa under normal BWR operation (Tokyo Electric Power Company, 2014) and the cyclic stresses due to transients were applied as the loading conditions in the crack growth evaluation. The cyclic stresses were specified by referring to that for BWR feed water system piping (JSME, 2002), which is close to target piping. The details of cyclic stresses are summarized in Table 3.

As described previously, PASCAL-SP can consider three types of weld failure modes, namely rupture, crack penetration, and leak. For the rupture evaluation, the Z-factor evaluation method provided in the JSME FFS code (JSME, 2012) was used to consider plastic collapse and ductile fracture. The flow stress was set as $329.4 \mathrm{MPa}$, whose value was obtained from a multiplication of the design stress strength by 2.7. The design stress strength at operation temperature of $302^{\circ} \mathrm{C}$ (Tokyo Electric Power Company, 2014) was set by referring to Codes for Nuclear Power Generation Facilities Rules on Materials for Nuclear Facilities- (JSME, 2012). Primary membrane stress of $38.2 \mathrm{MPa}$ and primary bending stress of $122 \mathrm{MPa}$ (Koriyama et al., 2009) were considered. The value of the Z-factor was set as 1.416, which was calculated from the formula for ferritic steel pipe in accordance with the JSME FFS code case NA-CC-002-1 (JSME, 2015). In addition, it was assumed that penetration of crack occurred when $a / t=0.99$. A weld was determined to be leaked when rupture or crack penetration occurred in this study.

The time and welds to be examined were specified based on the two sampling methods. Based on interval of NDEs prescribed as 10 years in the JSME FFS code (JSME, 2012), midterm of every 10-year interval was assumed as 
representative NDE time of interval in this analysis. That is, NDEs were implemented at the 5th, 15th, 25th, and 35th operation years.

Weld and interval to be examined based on the FLSM and the RLSM were summarized in Tables 4 and 5, respectively. In these tables, fractions refer to the extent of examination, and alphabets from $\mathrm{A}$ to $\mathrm{N}$ in uppercase refer to weld labels. Roman numerals indicate the interval to be examined corresponding to the extent of examination and weld label. $I, I I, I I I$, and $I V$ refer to the first, second, third, and fourth intervals and NDEs are implemented at the 5th, 15th, 25th, and 35th years, respectively. Here, welds were given priority on NDEs in order of weld A to weld N when there were multiple choices of welds to be examined based on the FLSM and RLSM. Blank spaces mean that NDE for the welds is not implemented during an operation.

For the FLSM (Table 4), welds examined in the last 10-year interval were examined. When extent of examination was $1 / 14$, the NDEs were implemented for weld A in the first, second, third, and fourth intervals. The number of welds subject for repeated NDEs increased as extent of examination increased. On the other hand, for the RLSM (Table 5), welds not examined in the last 10-year interval were examined. In addition, NDEs for welds which had not been examined for the longest time were given high priority in this analysis. For example, when the extent of examination is $1 / 14$ and weld $\mathrm{A}$ is examined in the first interval, a weld to be examined in the second interval is selected from welds B to N. If weld $\mathrm{B}$ is selected in the second interval, a weld for NDE in the third interval is selected from all welds except for weld B. However, since weld A was examined in the first interval, NDE is implemented to any of the welds $\mathrm{C}$ to $\mathrm{N}$. For such consideration, welds $\mathrm{C}$ and $\mathrm{D}$ are selected for NDEs in the third and fourth intervals, respectively. Here, it is noted that when extent of examination exceeded 7/14, there was no choice to select welds for NDEs from only those not examined in the last interval. Thus, in this situation, some welds examined in last intervals were re-examined.

In all NDEs, a POD curve considering performance of examination team was taken into account (Khaleel and Shimonen, 2009). In the analyses, parameters of the model listed in Table 6 were specified to consider outstanding performance of examination team for fatigue crack detection (Harris and Dedhia, 1998). Here, $a^{*}$ is crack depth when $\mathrm{POD}=0.5, v$ is the slope of the POD curve, $\varepsilon$ is the smallest probability of nondetection for very large cracks, and $D_{\mathrm{B}}$ is the beam diameter of ultrasonic probe. As POD shown in Fig. 2, a crack with $a / t>0.2$ can be detected with approximately $100 \%$. On the other hand, for a crack with $a / t<0.2$, POD value decreases as the crack size becomes small. All detected cracks were eliminated through repair or replacement in this analysis.

The failure probability of the piping $P_{F}$ was calculated using Eq. (1) based on the values of $f_{\mathrm{A}}$ to $f_{\mathrm{N}}$ obtained under the above analysis conditions. All cases of extent of examination from 0/14 to 14/14 were considered in this analysis. Afterwards, the relationship between the failure probability and the extent of examination was determined.

Table 1 Crack distributions and the existing probability

\begin{tabular}{|l|l|}
\hline \multicolumn{1}{|c|}{ Description } & \multicolumn{1}{c|}{ Value of parameter } \\
\hline Crack depth: $a[\mathrm{~mm}]$ & $\begin{array}{l}\mu=0.294[\mathrm{~mm}] \\
\sigma=1.61\end{array}$ \\
Lognormal distribution: $f(a)=\frac{1}{\sqrt{2 \pi} \sigma a} \exp \left(-\frac{1}{2}\left(\frac{\ln (a / \mu)}{\sigma}\right)^{2}\right)$ & $\begin{array}{l}\mu=1.336, \\
\sigma=0.538, \\
\text { Crack aspect ratio: } \beta\end{array}$ \\
Lognormal distribution: $f(\beta)=\frac{C}{\sqrt{2 \pi} \sigma \beta} \exp \left(-\frac{1}{2}\left(\frac{\ln (\beta / \mu)}{\sigma}\right)^{2}\right)$ & \\
\hline
\end{tabular}

Table 2 Parameters in the probabilistic evaluation model of CGR

\begin{tabular}{|c|l|l|l|}
\hline Stress ratio $R$ & \multicolumn{1}{|c|}{$R \leq 0.25$} & \multicolumn{1}{|c|}{$0.25<R<0.65$} & \multicolumn{1}{c|}{$0.65 \leq R$} \\
\hline$C_{1}$ & $1.48 \times 10^{-14}$ & $1.48 \times 10^{-14}(26.9 R-5.725)$ & $1.74 \times 10^{-13}$ \\
\hline$C_{2}$ & $2.13 \times 10^{-9}$ & $2.13 \times 10^{-9}(3.75 R+0.06)$ & $5.33 \times 10^{-9}$ \\
\hline$Q$ & $\exp \left(-0.408+0.542 C_{\mathrm{F}}\right)$ & $\begin{array}{l}\exp [(0.1025 R-0.433625 \\
\left.+(0.6875 R+0.370125) C_{\mathrm{F}}\right]\end{array}$ & $\exp \left(-0.367+0.817 C_{\mathrm{F}}\right)$ \\
\hline$\Delta K_{\text {th }}$ & 19.48 & $\left(C_{2} / C_{1}\right)^{0.25}$ & 13.23 \\
\hline \multicolumn{2}{|l|}{$C_{\mathrm{F}}:$ Normal distribution with mean of 0 and standard deviation of 1 }
\end{tabular}


Mano, Katsuyama and Li, Mechanical Engineering Journal, Vol.7, No.3 (2020)

Table 3 Cyclic stresses due to transient events

\begin{tabular}{|l|l|l|l|l|l|}
\hline \multirow{2}{*}{ Event no. } & $\begin{array}{c}\text { Number of events } \\
\text { [/year] }\end{array}$ & \multicolumn{2}{|c|}{ Membrane stress [MPa] } & \multicolumn{2}{c|}{ Bending stress [MPa] } \\
\cline { 3 - 6 } & & Min. & Max. & Min. & Max. \\
\hline 1 & 7 & 0.0 & 122.0 & 0.0 & 0.0 \\
2 & 18 & 48.8 & 183.0 & 0.0 & 0.0 \\
3 & 320 & 91.5 & 122.0 & 0.0 & 0.0 \\
4 & 8 & 0.0 & 0.0 & -122.0 & 122.0 \\
5 & 16 & 0.0 & 0.0 & -61.0 & 61.0 \\
6 & 330 & 0.0 & 0.0 & -12.2 & 12.2 \\
\hline
\end{tabular}

Table 4 Weld and interval for NDEs based on the FLSM

\begin{tabular}{|c|c|c|c|c|c|c|c|c|c|c|c|c|c|c|}
\hline \multirow{2}{*}{$\begin{array}{c}\text { Extent of } \\
\text { examination }\end{array}$} & \multicolumn{14}{|c|}{ Weld label } \\
\hline & A & B & C & D & E & F & G & $\mathrm{H}$ & $\mathrm{I}$ & $\mathrm{J}$ & $\mathrm{K}$ & $\mathrm{L}$ & $\mathrm{M}$ & $\mathrm{N}$ \\
\hline $0 / 14$ & & & & & & & & & & & & & & \\
\hline $1 / 14$ & \begin{tabular}{|l|}
$I, I I, I I I$ \\
$I V$
\end{tabular} & & & & & & & & & & & & & \\
\hline $2 / 14$ & \begin{tabular}{|l|}
$I, I I, I I I$ \\
$I V$
\end{tabular} & II, II, I & & & & & & & & & & & & \\
\hline : & & & & & & & & & & & & & & \\
\hline $13 / 14$ & \begin{tabular}{|l|}
$I, I I, I I I$ \\
$I V$
\end{tabular} & $\begin{array}{l}I, I I, I \\
I V\end{array}$ & $\begin{array}{l}I I, I I, \\
I V\end{array}$ & $I, I I, I$ & $\begin{array}{l}I, I I, I \\
I V\end{array}$ & $\begin{array}{l}I I I, I I, I \\
I V\end{array}$ & $I, I I, I$ & $\begin{array}{l}I, I I, I \\
I V\end{array}$ & $I, I I, I$ & $\begin{array}{l}I, I I, I \\
I V\end{array}$ & $\begin{array}{l}I I, I I, I \\
I V\end{array}$ & $\begin{array}{l}I, I I, I \\
I V\end{array}$ & $I, I I, I I I$ & \\
\hline $14 / 14$ & $\begin{array}{l}I, I I, I I I \\
I V\end{array}$ & $\begin{array}{l}\text { I, II, } \\
I V\end{array}$ & $\begin{array}{l}I I, I I, \\
I V\end{array}$ & $I, I I, I$ & $I, I I$, & $\begin{array}{l}I I I, I I, I \\
I V\end{array}$ & II, II, & $\begin{array}{l}I, I I, I \\
I V\end{array}$ & $\begin{array}{l}I, I I, \\
I V\end{array}$ & $\begin{array}{l}I I, I I, \\
I V\end{array}$ & $\begin{array}{l}I I, I I, I \\
I V\end{array}$ & $\begin{array}{l}I, I I, I \\
I V\end{array}$ & $I, I I, I I$ & $\begin{array}{l}I, I I, I \\
I V\end{array}$ \\
\hline
\end{tabular}


Table 5 Weld and interval for NDEs based on the RLSM

\begin{tabular}{|c|c|c|c|c|c|c|c|c|c|c|c|c|c|c|}
\hline \multirow{2}{*}{$\begin{array}{r}\text { Extent of } \\
\text { examination }\end{array}$} & \multicolumn{14}{|c|}{ Weld label } \\
\hline & $\mathrm{A}$ & $\mathrm{B}$ & $\mathrm{C}$ & $\mathrm{D}$ & $\mathrm{E}$ & $\mathrm{F}$ & G & $\mathrm{H}$ & $\mathrm{I}$ & $\mathrm{J}$ & $\mathrm{K}$ & $\mathrm{L}$ & $\mathrm{M}$ & $\mathrm{N}$ \\
\hline \multicolumn{15}{|l|}{$0 / 14$} \\
\hline $1 / 14$ & $1+$ & $I I$ & III & $I V$ & & & & & & & & & & \\
\hline $2 / 14$ & $I$ & $I$ & $I I$ & II & III & III & $I V$ & $I V$ & & & & & & \\
\hline $3 / 14$ & $I$ & $I$ & $I$ & $I I$ & $I I$ & II & III & III & III & $I V$ & $I V$ & $I V$ & & \\
\hline $4 / 14$ & $I, I V$ & $I, I V$ & $I$ & $I$ & $I I$ & $I I$ & $I I$ & II & $I I I$ & III & III & III & $I V$ & $I V$ \\
\hline $5 / 14$ & $I, I I I$ & $I, I V$ & $I, I V$ & $I, I V$ & $I, I V$ & $I I, I V$ & II & II & II & $I I$ & III & III & III & III \\
\hline 6 & $I, I I I$ & $I, I I I$ & $I, I I I$ & $I, I I I$ & $I, I V$ & $I, I V$ & $I I, I V$ & $I I, I V$ & $I I, I V$ & $I I, I V$ & $I I$ & $I I$ & III & $I I I$ \\
\hline $7 / 14$ & $I, I I I$ & $I, I I I$ & $I, I I I$ & $I, I I I$ & $I, I I I$ & $I, I I I$ & $I, I I I$ & $I I, I V$ & $I I, I V$ & $I I, I V$ & $I I, I V$ & $I I, I V$ & $I I, I V$ & $I I, I V$ \\
\hline $8 / 14$ & $I, I I, I V$ & $I, I I, I V$ & $I, I I I, I V$ & $I, I I I, I V$ & $I, I I I$ & $I, I I I$ & $I, I I I$ & $I, I I I$ & $I I, I I I$ & $I I, I I I$ & $I I, I V$ & $I I, I V$ & $I I, I V$ & $I I, I V$ \\
\hline $9 / 14$ & $I, I I, I V$ & $I, I I, I V$ & $I, I I, I V$ & $I, I I, I V$ & VI,III,IV & $I, I I I, I V$ & $I, I I I, I V$ & $I, I I I, I V$ & $I, I I I$ & $I I, I I I$ & $I I, I I I$ & $I I, I I I$ & $I I, I I I$ & $I I, I V$ \\
\hline $10 / 14$ & $I, I I, I I$ & $I I, I I, I I I$ & $I I, I I, I V$ & $I, I I, I V$ & $V I, I I, I V$ & $V I, I I, I V$ & $I, I I I, I V$ & $I, I I I, I V$ & $I, I I I, I V$ & $I, I I I, I V$ & $I I, I I I, I V$ & $I I, I I I, I V$ & III, III & $I I, I I I$ \\
\hline $11 / 14$ & $\begin{array}{l}I, I I, I I I, \\
I V\end{array}$ & $\begin{array}{l}I, I I, I I I, \\
I V\end{array}$ & $I, I I$ & $1 I$, & & & $I, I I, I V$ & $U$ & $I, I I I, I V$ & $I, I I I, I V$ & $I, I V$ & $I I, I I I, I V$ & III,III & III,II \\
\hline $12 / 14$ & $\begin{array}{l}I, I I, I I I, \\
I V\end{array}$ & $\begin{array}{l}I, I I, I I I, \\
V\end{array}$ & $\begin{array}{l}\text { II,II,III, } \\
I V\end{array}$ & $\begin{array}{l}I, I I, I I I, \\
I V\end{array}$ & \begin{tabular}{|l}
$I, I I, I I I$, \\
$I V$
\end{tabular} & $\begin{array}{l}I, I I, I I I, \\
I V\end{array}$ & $I, I I$ & $I I, I I$, & $I, I I, I V$ & $V I, I I, I V$ & $V I, I I I, I V$ & $I, I I I, I V$ & $I I, I I I, I V$ & II, III,I \\
\hline $13 / 14$ & $\begin{array}{l}I, I I, I I I, \\
I V\end{array}$ & $\begin{array}{l}I, I I, I I I, \\
I V\end{array}$ & \begin{tabular}{|l} 
I, III,III, \\
$I V$
\end{tabular} & $\begin{array}{l}I, I I, I I I, \\
I V\end{array}$ & $\begin{array}{l}I, I I, I I I, \\
I V\end{array}$ & $\begin{array}{l}I, I I, I I I, \\
I V\end{array}$ & \begin{tabular}{|l}
$I, I I, I I I$, \\
$I V$
\end{tabular} & $\begin{array}{l}I, I I, I I I, \\
I V \\
\end{array}$ & $\begin{array}{l}I, I I, I I I, \\
I V \\
\end{array}$ & $\begin{array}{l}I, I I, I I I, \\
I V\end{array}$ & $I, I I$, & $I, I I$ & $I, I I I, I$ & $I I, I I I$ \\
\hline $14 / 14$ & $\begin{array}{l}I, I I, I I I, \\
I V\end{array}$ & $\begin{array}{l}I, I I, I I I, \\
I V\end{array}$ & $\begin{array}{l}I, I I, I I I, \\
I V\end{array}$ & $\begin{array}{l}I, I I, I I I, \\
I V\end{array}$ & $\begin{array}{l}I, I I, I I I, \\
I V\end{array}$ & $\begin{array}{l}I, I I, I I I, \\
I V\end{array}$ & $\begin{array}{l}I, I I, I I I, \\
I V\end{array}$ & $\begin{array}{l}I, I I, I I I, \\
I V\end{array}$ & $\begin{array}{l}I, I I, I I I, \\
I V\end{array}$ & $\begin{array}{l}I, I I, I I I, \\
I V\end{array}$ & $\begin{array}{l}I, I I, I I I, \\
I V\end{array}$ & $\begin{array}{l}I, I I, I I I, \\
I V\end{array}$ & \begin{tabular}{|l}
$I, I I, I I I$, \\
$I V$
\end{tabular} & $\begin{array}{l}I, I I, I I \\
I V\end{array}$ \\
\hline
\end{tabular}

Table 6 POD evaluation model and its parameters

\begin{tabular}{|c|c|c|c|c|}
\hline POD evaluation model & $a^{*}[\mathrm{~mm}]$ & $v$ & $\varepsilon$ & $D_{\mathrm{B}}[\mathrm{mm}]$ \\
\hline POD $=1-\varepsilon-\frac{1}{2}(1-\varepsilon) \operatorname{erfc}\left(v \ln \frac{A}{A^{*}}\right)$ & & & \\
$A=\frac{\pi}{2} a c \quad\left(2 c<D_{\mathrm{B}}\right)$ & $0.05 t$ & 1.6 & 0.005 & 25.4 \\
$A=\frac{\pi}{4} a D_{\mathrm{B}} \quad\left(2 c \geq D_{\mathrm{B}}\right)$ & & & & \\
$A^{*}=\frac{\pi}{4} a^{*} D_{\mathrm{B}}$ & & & & \\
\hline
\end{tabular}

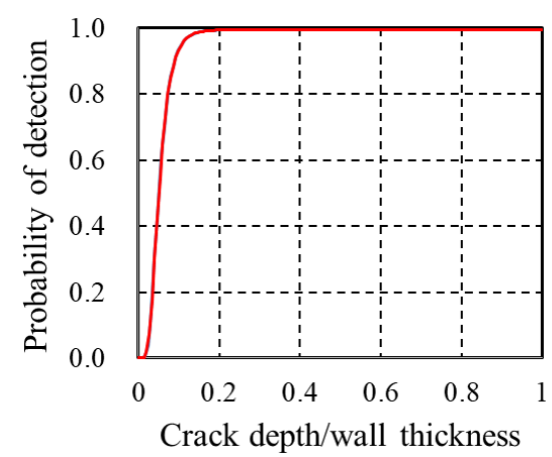

Fig. 2 POD curve used in this analysis. Here, outstanding performance NDE for a fatigue crack was considered. A crack with $a / t \geq 0.2$ can be detected with approximately $100 \%$. On the other hand, for a crack with $a / t<0.2$, POD value decreases as the crack size becomes small.

\subsection{Example analysis results}

Figures 3 and 4 represent the failure probability values against operation time for the FLSM and RLSM when extent of examination is $1 / 14$, respectively. Here, only analysis results for welds A, B, C, and D are plotted in the figures because 
NDE-related analysis conditions for other than the four welds were same in the two sampling methods, as described in Tables 4 and 5 .

In Fig. 3, the orange solid line indicates the failure probability values without NDE for the welds B, C, and D. Note that because failure probability values were same among the three welds, they are plotted in a single line. In this case, failure probability monotonically increased with operation time. The black solid line indicates the failure probability of weld A. As described in Table 4, NDEs were implemented at weld $\mathrm{A}$ in the first, second, third, and fourth intervals. In this case, failure probability was reduced by NDE compared with the case in which NDE was not applied. However, NDEs in the second to fourth intervals had little effect on failure probability reduction because crack initiation during operation was not considered in this study. Moreover, because of high POD shown in Fig. 2, almost all large cracks which can cause the failure of the target weld were detected and eliminated through the first NDE in addition to the radiographic inspection after fabrication. Thus, in this analysis conditions, it can be considered that only the first NDE for a weld reduces failure probability.

On the other hand, in Fig. 4, the black, blue, green, and red solid lines indicate the failure probability values of welds A, B, C, and D, respectively, when RLSM was applied. For each weld, NDE was implemented in the first, second, third, or fourth interval as described in Table 5. In this case, NDEs reduced the failure probability values in welds A to D. Nevertheless, amounts of reduction in weld A was higher than any of other three welds. Moreover, it was found that first NDE in the earlier interval reduced more failure probability of a weld in this analysis conditions.

Figure 5 shows the results based on the two sampling methods at 40th operation year when extent of examination was 1/14. The results illustrated with striped and uniform patterns in gray are based on FLSM and RLSM, respectively. Comparing the results between the two sampling methods, failure probability values of weld A indicate almost similar values regardless of the difference in the number of implemented NDEs. This is because that as stated earlier, only the first NDE for a weld reduced failure probability. On the other hand, failure probability values of the welds B, C, and D are lower in the RLSM than the FLSM. Since failure probability of the piping is calculated by using those of welds including these four welds, it is considered that the failure probability of piping based on the RLSM will become lower than that based on the FLSM.

Considering NDEs based on the two different sampling methods summarized in Tables 4 and 5, the failure probability of the piping for all cases of extent of examination were calculated using the failure probability of each weld and Eq. (1). Figure 6 illustrates the relationship between the failure probability at the 40th year and the extent of examination. Circle symbols and cross symbols represent the results for the FLSM and RLSM, respectively. When the fractions of extent of examination are $0 / 14$ and 14/14, same values in failure probability of piping were yielded based on the two sampling method because NDE-related analysis conditions were the same in the two situations as shown in Tables 4 and 5 . For the rest of extent of examination, the lower failure probability values of piping were yielded by the RLSM as previously considered. In addition, it is found from Fig. 6 that the reduction tendency in failure probability based on the RLSM against the extent of examination was different between small and large extent of examination. For extent of examination less than around 4/14, the failure probability for the piping decreased largely with increase in the extent of examination. This is because that NDEs which were the first time for welds had large effect on decreasing failure probability as previously explained, and the number of such NDEs increased as summarized in Table 5. For extent of examination larger than around $5 / 14$, failure probability for piping decreased a little with increase of the extent of examination. The reason for this is as follows. From Table 5, the number of examined welds did not increase, but the time of implementation for the first NDE changed to one interval earlier with an increase in the extent of examination. Thus, the decrease in failure probability was not as large as when the extent of examination was lower than 4/14.

Based on the results of these analyses, the RLSM can consider to be better choice for NDEs under this analysis condition to achieve lower failure probability against extent of examination. It should be noted that this sampling method is different from that prescribed in the code such as the JSME FFS code, which applies the FLSM under the consideration that it is important to grasp the degree of degradation such as crack growth due to SCC or fatigue. In case of such consideration, the selection of the FLSM is reasonable. Based on these considerations on the two sampling methods, it is suggested that failure probability obtained from the PFM analysis is supplementary used as a numerical index for the selection of reasonable sampling methods related to NDEs. 


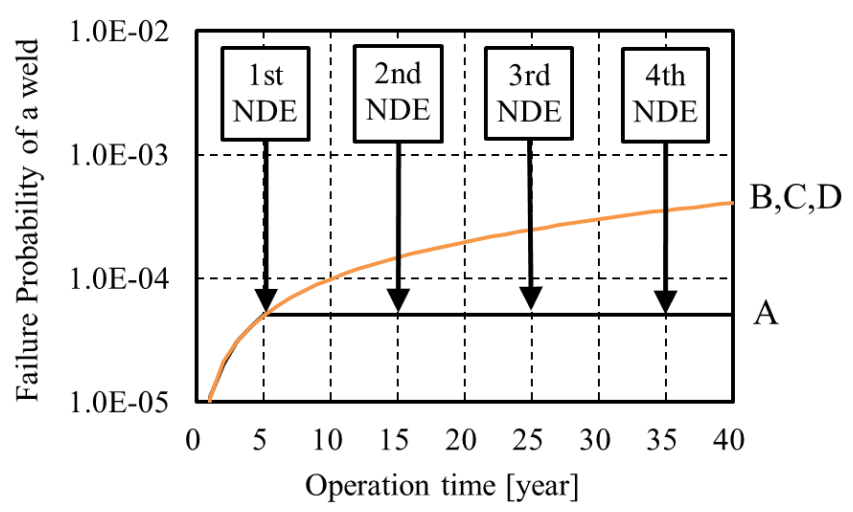

Fig. 3 Failure probability against operation time in the case of FLSM. The failure probability values of welds B, C, and $\mathrm{D}$, which correspond to the cases that NDEs were not performed, monotonically increased with operation time. On the other hand, increase in the failure probability value of weld A was mitigated by NDEs.

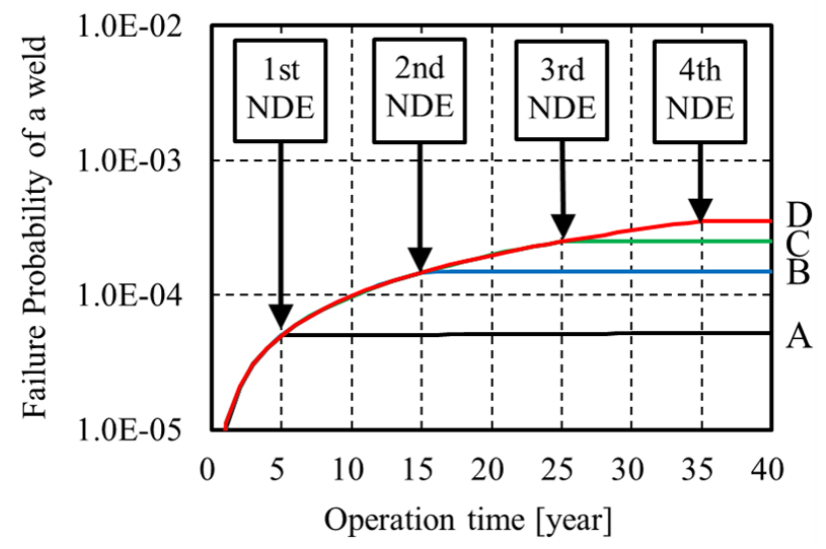

Fig. 4 Failure probability against operation time in the case of RLSM. Here, welds A, B, C, and D were examined at 1st, 2nd, 3rd, and 4th intervals, respectively. The increases in the failure probability values of the four welds were mitigated by NDE at each interval. The implementation of NDE at earlier interval provided lower failure probability at 40 th operation year.

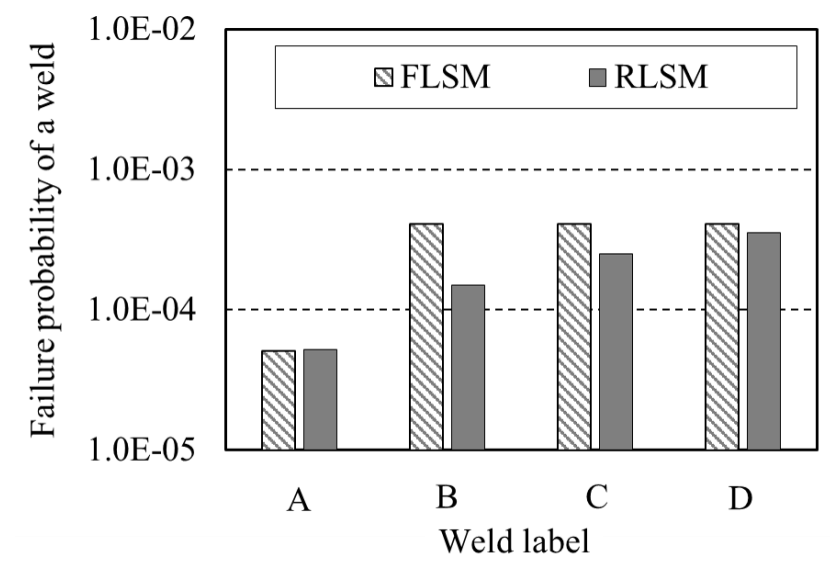

Fig. 5 Comparison in failure probability values between the cases of FLSM and RLSM. The results illustrated with striped and uniform patterns are the failure probability values at 40th operation year based on FLSM and RLSM, respectively, when extent of examination was assumed as 1/14. Comparing the results between FLSM and RLSM, it is found that RLSM provided lower failure probability through NDEs for multiple welds in this analysis condition. Although weld A was examined multiple times in FLSM, the failure probability values of weld A obtained from different two sampling methods were almost same. 


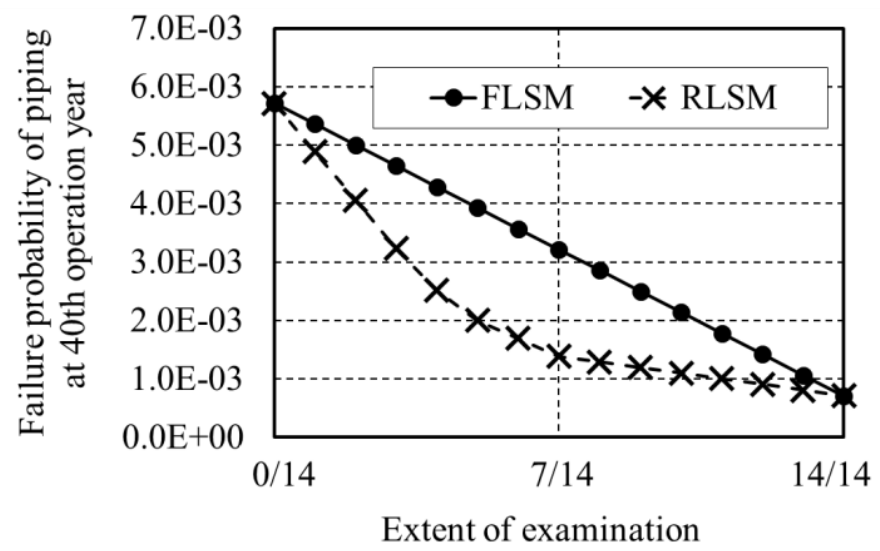

Fig. 6 Failure probability of piping as a function of extent of examination. Circle and cross symbols represent the failure probability values at 40th operation year for the FLSM and RLSM, respectively. The failure probability values decreased with increase of extent of examination in both cases of FLSM and RLSM. Under the conditions of this analysis, the failure probability based on RLSM was lower than that based on FLSM.

\section{Conclusion}

In this study, the quantitative influence of the difference between FLSM and RLSM on failure probability of a typical nuclear piping was clarified through the calculation by using a PFM analysis code PASCAL-SP. From the results, it is concluded that the PFM analysis is useful because the two sampling methods can be relatively compared by using failure probability as a numerical index. Moreover, PFM analysis can provide information for the sampling method which provides lower failure probability of the piping.

\section{References}

American Society of Mechanical Engineers, 2015, ASME Boiler and Pressure Vessel Code Section XI Rules for Inservice Inspection of Nuclear Power Plant Components, BPVC-XI-2015, New York.

Brückner A. and Munz D., 1982, Curve Fitting to Defect Size Distributions for the Calculation of Failure Probabilities, Nuclear Engineering and Design 74, pp.75 -78.

Harris D. O. and Dedhia D. D., 1998, WinPRAISE 98 PRAISE Code in Windows, Technical Report TR-98-4-1, Engineering Mechanics Technology inc.

Harris D. O., Lim E. Y. and Dedhia D. D., 1981, Probability of Pipe Fracture in the Primary Coolant Loop of a PWR Plant, NUREG/CR -2189.

Itoh H., Kato D., Osakabe K., Nishikawa H. and Onizawa K., 2010, User's Manuals of Probabilistic Fracture Mechanics Analysis Code for Aged Piping, PASCAL-SP, JAEA-Data/Code 2009-025.(in Japanese)

Japan Electric Association, 1996, Inservice Inspection of Light Water Cooled Nuclear Power Plant Components, JEAC4205-1996. (in Japanese)

Japan Society of Mechanical Engineers, 2015, JSME Code Case - Alternative Rule of Acceptable Circumferential Flaw Angle Limit -, JSME S NA1-2015 NA-CC-002-1. (in Japanese)

Japan Society of Mechanical Engineers, 2012, Codes for Nuclear Power Generation Facilities - Rules on Fitness-forService for Nuclear Power Plant -, JSME S NA1-2012. (in Japanese)

Japan Society of Mechanical Engineers, 2012, Codes for Nuclear Power Generation Facilities - Rules on Materials for Nuclear Facilities-, JSME S NJ1-2012.(in Japanese)

Japan Society of Mechanical Engineers, 2002, Codes for Nuclear Power Generation Facilities - Rules on Protection Design against Postulated Pipe Rupture for Nuclear Power Plants -, JSME S ND1-2002. (in Japanese)

Khaleel F. A. and Shimonen F. A., 2009, Evaluations of Structural Failure Probabilities and Candidate Inservise Inspection Programs, NUREG/CR-6986.

Koriyama T., Li Y., Hamaguchi Y., Yamashita M. and Hirano M., 2009, Study on Risk-Informed In-Service Inspection for BWR Piping, Journal of NUCLEAR SCIENCE of TECHNOLOGY, Vol. 26, No. 8, pp.846-873.

Tokyo Electric Power Company, 2014, Reports on Aging Technical Evaluation - Piping Technical Evaluation for Kashiwazaki-Kariwa Nuclear Power Station Unit 1-. (in Japanese)

Westinghouse Electric Company, 1999, Westinghouse Owners Group Application of Risk Informed Methods to Piping 
Inservise Inspection Topical Report, WCAP-14572 Revision1-NP-A.

Westinghouse Electric Company, 2012, Risk-Informed Extension of the Reactor Vessel Nozzle Inservice Inspection Interval, WCAP-17236-NP-A Revision 0. 